\title{
The importance of social emotional learning skills in assisting youth to successfully transition into the professional world
}

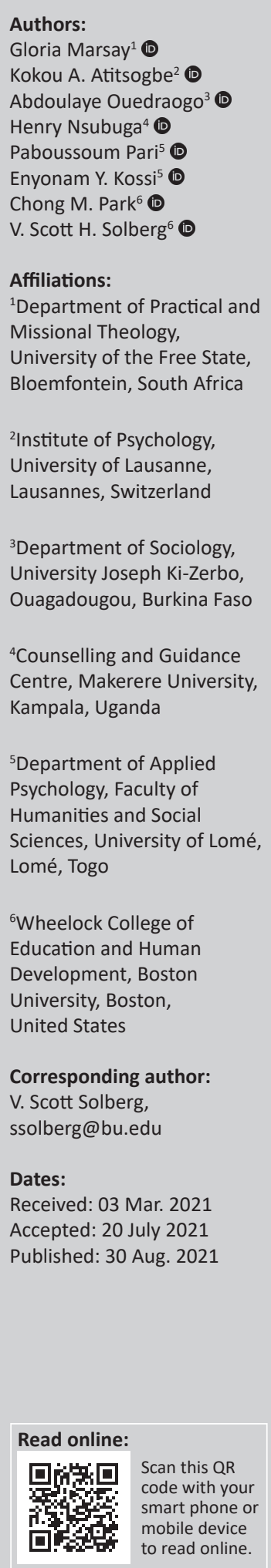

Background: This article shares the results of research on educator perceptions of the nature and value of social emotional learning (SEL) skills undertaken in four African countries: Burkina Faso, South Africa, Togo and Uganda. Social emotional learning skills make up a large component of the 'deep human skills', which are important academic and workforce development skills.

Objectives: Using samples of 50 Burkinabe, 68 South African and 32 Togolese and 66 Ugandan educators, this study describes the (1) SEL skills educators should be using to effectively teach their students and the (2) SEL skills the educators believe students should be using to be effective learners and successfully transition into the world of work.

Method: Data collection methods include online and offline surveys, with the exception of Uganda that complemented their survey data with interviews. Thematic content analysis, using modified grounded theory, was used to analyse the data, as well as the qualitative data analysis software NVivo.

Results: The results indicated seven common SEL themes shared across the four African countries. The SEL themes identified were consistent with the existing framework of Collaborative for Academic, Social and Emotional Learning (CASEL) to some extent, especially around interpersonal relationships and decision-making skills.

Conclusion: The findings indicate that the salience and importance of specific SEL skills varied based on the unique history and context of each country.

Keywords: social emotional learning; career; future readiness; positive youth development; cross-cultural study.

\section{Introduction}

Internationally, 'social emotional learning' (SEL) is considered a core element in K-12 education (Collaborative for Academic, Social, and Emotional Learning [CASEL], 2021). Social emotional learning was initially launched conceptually as a framework by CASEL and is now widely adopted throughout the United States (CASEL, n.d.). The CASEL is an independent nongovernment or non-profit organisation that was originally part of the University of Illinois, Chicago, United States of America that continues to develop free-access resources to help education systems adopt and effectively engage in SEL-related activities, establish learning standards and assessment for schools and allow researchers to have theoretical and methodological reflections (CASEL, n.d.). The CASEL framework involves five SEL categories: self-awareness refers to one's understanding of his or her emotions, thoughts, values and talent and one's awareness that these may affect their interpersonal relationships. Self-management refers to one's ability to effectively manage his or her emotions, thoughts and values in ways that enable them to develop and maintain positive interpersonal relationships, pursue desired goals and experience positive outcomes. Social awareness refers to one's ability to understand the perspectives of others based on different cultural and life experiences and thereby express empathy and compassion. Relationship skills refer to one's ability to establish and maintain positive collaborations and engage in problem-solving to resolve differences. Responsible decision-making skills refer to making effective decisions about one's behaviour in social interactions, as well as consider future goals.

How to cite this article: Marsay, G., Atitsogbe, K.A., Ouedraogo, A., Nsubuga, H., Pari, P., Kossi, E.Y., ... Solberg, V.SH. (2021). The importance of social emotional learning skills in assisting youth to successfully transition into the professional world. African Journal of Career Development, 3(1), a37. https://doi.org/10.4102/ajcd.v3i1.37

Copyright: ๑ 2021. The Authors. Licensee: AOSIS. This work is licensed under the Creative Commons Attribution License. 
For younger students, SEL is an important foundation for creating positive classroom experiences that enable youth to develop emotionally and academically. Meta-analysis of SEL interventions has verified the positive impact of developing SEL skills on a range of academic outcomes (Durlak, Weissberg, Dymnicki, Taylor, \& Schellinger, 2011). Social emotional learning skills also serve as a foundation for positive mental health and well-being by helping youth learn how to navigate and negotiate their interpersonal activities in ways that help them achieve desirable outcomes (Taylor, Oberle, Durlak, \& Weissberg, 2017). Finally, SEL skills also serve as 'deeper human skills' that are critical to becoming successful in the world of work (Lim-Lange \& Lim-Lange, 2019; Yoder, 2015). Internationally, the European Union and the Organisation Economic Cooperation and Development have identified SEL skills as core to education (Cefai, Bartolo, Cavioni, \& Downes, 2018; Cefai, Regester, \& Akoury-Dirani, 2020; OECD, 2016). In the African context, SEL has been discussed in relation to supporting mental health amongst Nigerian youth experiencing trauma (Kim, Brown, \& Weiss-Yagoda, 2017) and is integrated into a reading skills strategy as the foundation for healing and supports needed to improve both academic and mental health outcomes for Congolese youth (Aber et al., 2016).

This study sought to understand educator perspectives from four African countries (Burkina Faso, South Africa, Togo and Uganda) about their perspectives on the nature and value of SEL skills. The study design was informed by a growing awareness amongst researchers to include the voices and realities of those we study in order to more accurately reflect their lived experiences (Santos, 2018). To address these social justice concerns, this cross-cultural study used qualitative research methods to allow the voice of educators from four African countries to shape a narrative regarding the nature and applicability of SEL skills in helping to manage classroom functioning and prepare youth to enter the world of work.

Whilst the results of this study reflect research conducted by four countries from the Global South, namely Burkina Faso, South Africa, Togo and Uganda, the programme of research was conducted as part of an SEL International Research Network (SEL IRN) consisting of 18 countries from around the world and was formally recognised by the World Educational Research Network in 2019 (WERA, n.d.). Operating as a collaborative community of researchers, the SEL IRN supported teams around qualitative research design and analysis, considering questions that would facilitate educator engagement. Each research team maintained their autonomy by deciding on the final versions of their questions, format for engaging with educators (e.g. survey, interview, focus groups), selecting the sample of educators they wished to involve in the study and analysing their results. The contextual information of each of the four countries, especially the challenges students and educators experience in accessing quality education, including SEL and career development is discussed next.

\section{The Burkinabe context}

In Burkina Faso, there are many challenges that hinder students from accessing quality education regardless of their gender, income and/or place of residence (UNESCO, 2017). Whilst $70 \%$ of the population was made up of youth and young adults under the age of 25 in 2015, the elementary school completion rate was 57\% in 2013 and 2014. It was estimated that over 41\% of school-age children are outside the school system. The Burkina Faso National Education System Status Report (UNESCO, 2017) assessed gender disparities and indicated that the risk of dropping out of school is slightly higher amongst girls (54.7\%) than in boys (51.8\%). The risk of being out of school in rural areas is much higher at $50 \%$ than in urban areas (30.2\%) (INSD, 2018)

Basic education in Burkina Faso is compulsory and free for all children between the ages of 6 and 16 that cover preschool, primary and secondary levels (Law No. 013-2007 / AN; Education Orientation Law). Basic education aims to develop students' physical, emotional, intellectual and artistic potential, promote the empowerment of learners and facilitate their social integration (Burkina Faso, 2007). However, the Education Orientation Law lacks details and guidelines on the types of social and emotional skills that need to be taught. The topic is currently taken into account in counseling and guidance education for pre-service teachers (Kaboré \& Nabaloum, 2014). Considering the number of youth who are out of the school system or do not complete primary education, discussion on how to prepare youth for the world of work is a great concern of Burkinabe educators, especially with the SEL skills that would help them smoothly transition to the world of work.

\section{South African context}

The Department of Higher Education and Training (DHET) has identified three major challenges in South Africa: poverty, inequality and unemployment (DHET, 2016). There is often a disconnect between skills development policies, economic policies, social protection and education policies (De Lannoy, Graham, Patel, \& Leibbrandt, 2018; DHET, 2019; Lund, 2016; Eds. Spaull \& Jansen, 2019). Classroom environments in South Africa are not always conducive to learning (Leoschut \& Kafaar, 2017; Makota \& Leoschut, 2016; Mfidi, ThuayagaleTsheneagae, \& Akpor, 2018; Mncube \& Maphalala, 2014; Romero, Hall, \& Cluver, 2019; Teeger, 2015). Educators are often primary caregivers and role models of children, especially those children from child-headed households (Cluver, Orkin, Gardner, \& Boyes, 2012; Dass-Brailsford, 2005; Jansen, 2013, 2019; Mohlakwana, 2013). Research informs us that the mental health of both educators (Moyo \& Perumal, 2019) and learners (Mfidi, 2017; Skinner, Sharp, Marais, Serekoane, \& Lenka, 2019) interferes with students' cognitive development and learning and teachers' input. From this background, a strong case can be made for the importance of implementing Social and Emotional Learning skills interventions for improving the learning environment and assisting young people to become more future-orientated. 
In the South African context, young people need to be more aware of looking for opportunities to earn a sustainable livelihood rather than making 'career' decisions (Marsay, 2020a, 2020b). The traditional concept of 'career' is fragmenting at a rapid pace in the Fourth Industrial Revolution and is not always relevant in the South African context of adversity, where unemployment is rated as one of the highest in the world. Instead, youth need to be employable, self-empowered and confident enough to find opportunities to earn a sustainable livelihood. This means that they should be equipped with workplace and advanced human skills, such as self-awareness, social awareness, interpersonal relationships and effective communication skills. Students are not just future workers, but future adults, parents, role models, citizens and decision makers. The implementation of SEL programmes can provide the skills they need and empower and enable them to make a successful transition from school to adulthood and the world of work.

\section{Togolese context}

The transition from education to work is of great challenge for both students and public authorities in Togo as shown in its high youth unemployment and underemployment rates. It was reported that graduate students take their first job 35 months after completing their degree, on average, and one-quarter of them experience difficulties in making a satisfactory transition to work (OECD, 2016). Problems also exist in school - only $12.3 \%$ of secondary school learners have access to higher education. In this constraining environment, students often seek the help of educators and their role becomes even more important when students make a career decision.

Given the important role of educators in the Togolese context, the examination of their perceptions on social and emotional learning skills is timely and provides insights into the skills needed for Togolese educators and learners. Many studies suggest that the norms in the country are strongly rooted in tradition. For example, Kazimna et al. (2020) reported that the respect of local norms was part of the conceptualisation of decent work by Togolese adult workers. The awareness of adolescents regarding their cultural values also underlies their occupational preferences and choices (Atitsogbe \& Bernaud, in preparation). Research suggests that complying with social norms is particularly important in the sub-Saharan Africa context, requiring further examination when discussing SEL education (Nsamenang, 1992).

\section{Ugandan context}

In Uganda, there are many challenges that hinder youth from accessing educational opportunities, especially amongst girls, children with disabilities, minorities and the displaced. The inequality was found to increase as one departs from the capital city. The completion rate of Primary 7 , which is the last stage of basic education, was $9.6 \%$ and for rural areas, it was as low as $6.1 \%$. According to the
Gender Parity Index (GPI) of the 2016 national census report, there were more boys than girls in school at both primary and secondary levels.

The interviews conducted by the Ugandan research team provide additional contextual information on the challenges when discussing SEL education. As an additional outcome of this qualitative research, it was found that only a small number of university teacher trainers make an effort to teach how to acquire SEL skills, and many do not consider it as their duty to teach SEL skills. A limited number of the school administrators and government officials were aware of the legislative plans to teach SEL skills whilst others were unaware of such plans. The school headmasters stated that the school system does not allow time for teachers to directly teach SEL skills, mainly because they are not part of the academic assessments, although they believe that SEL skills will help students later in life.

The testimonies from Ugandan educators show that there is an urgent need to create a system and programmes that would help youth and educators see the value of SEL and its connection to helping youth transition to secondary education and the workplace. When combined with SEL, it is possible to provide a brighter future to all of our students by increasing their chances of gaining access to decent work opportunities.

\section{Method Participants}

A total of 50 Burkinabe educators from Burkina Faso participated in the survey (40 male and 10 female) from urban (16), rural areas (27) and suburban settings (7). A total of 26 educators worked in secondary school and 24 in primary school settings. A total of 37 participants (74\%) were educators and $13(26 \%)$ were classified as other educators that include headmasters, inspectors and supervisors.

A total of 68 South African educators participated in the survey (gender information was not collected). All participants work in secondary school and teach grades 10 12. Altogether 19 educators were working with children who were deaf or with learning disabilities, whilst the remaining 59 were general education educators. A total of 45 participants were located in urban areas and 23 participants were located in rural areas and collectively they represent a wide range of multicultural backgrounds and schools in Gauteng, KwaZulu-Natal and Western Cape.

A total of 32 Togolese educators participated in the survey (27 male and five female). In all, 22 were teachers working in the primary and secondary schools and 10 were headmasters or career counsellors. A total of 19 educators worked in urban settings, nine in suburban settings and four in rural areas.

A total of 48 Ugandan educators participated (gender information was not collected). The participants included 
pre-service teacher trainees in their final year of study, inservice teachers in the primary level (Grade 5) and university faculty who teach graduate-level courses. To have a deeper understanding of educator perceptions, the research team also conducted interviews with 10 teacher trainers or university faculty and eight school managers and government officials. All participants were located in the capital and attending or teaching at Makerere University.

\section{Procedure}

In order to collect and represent educator perceptions of the nature and potential value of SEL, SEL IRN collaborated in designing a set of open-ended questions countries to consider when designing their final survey. The researchers in each country team maintained their autonomy in executing research by adapting the content of the questions, translating the survey and the choice of data collection strategies that suited their specific country and cultural context. Whilst each country adapted their surveys to suit their unique context, all four countries collected information on the background of their educator participants and provided open-ended questions to establish perceptions of educators regarding SEL skills in the learning environment. Educators' questions regarding the nature of SEL were designed to answer two research questions: (1) What SEL skills do educators believe they should be using to effectively teach their students and (2) What are educators' perceptions of the SEL skills young people need in order to successfully transition from education and training into the world of work. For the second research question regarding student SEL skills, open-ended questions were developed using five SEL categories offered by CASEL. Here is the common set of survey questions:

- Does your school or organisation offer SEL programmes or activities?

- If yes, please describe the activities or programmes being implemented.

- In relation to having an impact on students' learning and engagement in school:

- What SEL skills do you believe educators should be using to effectively teach their students? How are these skills helpful as educators?

- In relation to having an impact on students' learning and engagement in school:

- Please describe a situation or example or episode in which SEL skills can help educators work more effectively with students.

- In relation to having an impact on students' learning and engagement in school:

Please describe how the following list of SEL and other related skills are relevant in helping educators support youth specifically in making successful postsecondary transitions and/or preparing to enter the world of work:

- Self-awareness: The ability to accurately recognise one's emotions, thoughts and values and their influence on behaviour (e.g. recognising strengths and self-efficacy).
- Self-management: The ability to regulate one's emotions, thoughts and behaviours effectively in different situations (e.g. stress management, self-motivation and goal setting).

- Social awareness: The ability to understand the perspectives of others, including those from diverse backgrounds and cultures (e.g. empathy and respect for others).

- Relationship and communication skills: The ability to establish and maintain healthy and rewarding relationships with diverse individuals and groups (e.g. communication and teamwork).

- Decision making: The ability to make constructive and respectful choices about personal behaviour and social interactions based on ethical standards, safety concerns, social norms, the realistic evaluation of consequences and the well-being of self and others.

- Other skills (please specify).

All four countries used an online survey to collect educator responses, with South Africa providing an option of completing it on paper and Uganda conducting additional interviews. After an initial round of the online survey in South Africa, it was apparent that only a limited number of survey responses were valid and included in the analysis. The remaining surveys were completed using the paper and pencil method. The chosen language for the questionnaire was English. As a result of the multiple languages spoken in South Africa, there was someone present to interpret questions for those participants whose first language was not English. All the answers received were in English.

\section{Plan for analysis}

Each country team received professional training on how to engage in modified grounded theory as a qualitative analytic strategy that helped to gain a richer understanding of the data collected. In conducting the modified grounded theory analyses, each country team performed its own independent analysis. In conducting the analysis, each team reviewed the educator responses without categorising them into specific questions, identified emerging themes or codes and refined the codes as they collected more data. Whilst most country teams identified emerging themes or codes regardless of the survey questions asked, a few decided to separate the data focussed on educator perceptions of students' SEL skills from the data focussed on educators' SEL skills. The thematic analysis used in this study is a modified version of the steps described by Braun and Clarke (2006): (1) Using a few sample responses, teams familiarised themselves with the data, (2) each research team member identified ideas that have meanings, created an initial list of codes and compared the codes with another coder/s (member check), (3) with the code list, teams expanded their analysis to a larger number of responses, (4) teams reviewed their codes and made modifications to refine or identify better code terms and organised them into general themes and (5) generated a final codebook by creating a definition and identifying a 'best' example for each theme. 
The research teams in Burkina Faso, South Africa and Togo used NVivo software to organise the data, which led us to produce higher-level themes by clustering the codes or themes that have similar responses (NVivo Cluster Analysis). Qualitative cluster analysis allowed the researchers to construct the overall structure of the data (Guest \& McLellan, 2013). This was carried out by calculating correlations between codes using the Pearson correlation coefficient, based on word similarities in educator responses (Bazeley \& Jackson, 2013). The intention of the qualitative cluster analysis was to support the findings from the initial analysis using the modified grounded theory and gain a rich understanding of the data in the context of these four countries. The research team in Uganda conducted a thematic analysis using the steps described here but did not have access to NVivo software to provide additional support to their findings.

For this article, the research group consisted of four African country teams and the United States of America team as peerreviewers. The research group used an inductive approach to compare and organise the commonalities and differences, which emerged from the findings of each country.

\section{Ethical considerations}

Boston University Institutional Review Board determined that this research was exempt from IRB guidelines for informed consent because responses from the adult age educators were anonymous and the data did not ask them to evaluate their own capacities but to serve as experts in identifying quality educational practices.

\section{Results}

The results are described for each country team in the order of Burkina Faso, South Africa, Togo and Uganda. Using the modified grounded theory method, each country generated different SEL categories grounded in the voice of their educator respondents. Although the educator responses were often unclear whether they were referring to the SEL skills educators should be using or students should learn to be effective learners, the findings were, when possible, labelled to differentiate the responses concerning different populations.

\section{Burkina Faso}

There were five SEL categories identified from the Burkinabe educators' responses.

\section{Self-awareness}

Educators: Self-knowledge was identified as an important skill for Burkinabe educators. Five themes were found related to self-awareness: confidence and self-esteem, knowing your role well, challenging yourself, being rigorous and disciplined and self-motivation. Educators reported that it is important to feel comfortable and be aware of their own emotions in order to better teach their students. Educators also reported that it is important to set a learning goal and stick to it despite difficulties they might encounter.
Students: The educators reported that self-awareness is important for students in developing their self-confidence, 'they can make mistakes in their learning process, to accept their mistakes and ... to make their self-criticism before making their way towards efficiency based on their strengths'.

\section{Communication and interpersonal relationships}

Educators: Three themes emerged from the educator. Responses regarding communication and interpersonal skills: consideration or fairness, cooperation and relational leadership. To facilitate and improve learning, educators reported that it is important to promote cooperation and mutual respect amongst students. Relational leadership was identified as an important skill that enables educators to unite their students around a work goal that promotes acceptance of their authority.

Students: For students, educators reported that communication and interpersonal skills help them to work more effectively with their peers by, for example:

'[C]ontributing to their open-mindedness so that they will not be arrogant, whimsical persons but will be able to build consensus on the important issues they will face in their professional/ active life. In short, they will be builders and not destroyers'. (Ibrahim, Teacher, July 2020)

\section{Social consciousness}

Educators: Educators reported that developing 'social consciousness' is important and refers to their knowledge of the environment and context. Specific SEL skills in this category that the educators believed are important for themselves include cultivating a group spirit whereby they and their students are able to 'accept and integrate divergent opinions', cultivate openness to others by 'respecting others social values', as well as establishing respect and tolerance for others by being able to express 'forgiveness'.

Students: Educators reported that social consciousness helps students appreciate differences by helping them:

' $[R]$ ealise individually that he or she is not the centre of the earth and that he or she lives in the midst of other children whom he or she must know, respect and consider their opinion'. (Yasmine, Teacher, July 2020)

\section{Self-management}

Educators: Educators identified self-management as an important skill that helps them to promote participatory learning amongst students.

Students: For students, educators reported that selfmanagement skills enable them to become committed to learning, empowered and able to build self-confidence and self-control:

'It allows the student to be free and master of his learning. The child experiments, touches, smells, tastes, manipulates and achieves his results from a well-defined objective. This allows him to organise himself and plan his activities'. (Mohamed, Teacher, July 2020) 


\section{Decision making}

Educators: Educators reported that decision making is an important skill for creating collegiality when educators learn how to listen and take into account the diverse opinions of others. For example, one educator reported that it is important to 'take others into account in decision making for a more effective achievement of one's objectives'. Educators observed that when decisions reflect the interests of the students, they strengthen the authority of the educators. To develop students' decision-making skills, educators reported that it is important to encourage them to learn how to express their opinions in ways that consider weighing ideas both 'for' and 'against' a particular decision.

\section{South Africa}

A total of seven themes were identified from the responses of South African educators. The themes most frequently reported were interpersonal relationship skills (32\%), self-management $(19 \%)$, social awareness $(18 \%)$, positive impact on learning (16\%), improved educator efficacy $(7 \%)$, self-awareness (4\%) and decision making (3\%). Responses from educators illustrated how SEL skills would be of benefit to both educators and learners. The responses of South African educators also show their support for positive youth development, for example, one educator observed:

'There are learners who have behavioural problems. If the SEL skills are applied, the learners will understand and therefore learn to manage their emotions which will, in turn, result in a positive learning environment'. (Kaya, Teacher, May 2019)

\section{Interpersonal relationship}

Educators: The theme most frequently reported was interpersonal relationship skills. Educators reported that the ability to achieve effective interpersonal relationships has a positive impact on their own well-being and the learning environment. Educators reported that their ability to establish interpersonal relationships enables them to manage the classroom dynamics more effectively.

Students: Educators reported that when students develop interpersonal skills there is less likelihood of classroom 'friction and stressful situations' to emerge, which then leads to 'positive working outcomes'.

\section{Self-management}

Students: Educators reported that self-management is the most important skill for students, especially when making the transition from education into the world of work. The responses grouped in this theme focussed on personal organisational skills and self-control, including the ability to set goals, manage time, be self-disciplined and regulate and manage one's emotions. A sample response includes: 'Self-management promotes discipline. Learners manage their behaviours in correspondence with their goals'. Another educator expressed how: '[s]elf-management helps young people understand that they may be alone in the endeavours and that they need to rely on positive coping mechanisms, which can be developed in the classroom'.

\section{Social awareness}

Educators: Given the many cultures represented in each class, educators reported that social awareness skills are paramount for creating a positive learning environment. Educators felt that social awareness skills such as empathy and understanding how to improve their own efficacy and well-being are necessary to create an inclusive and supportive classroom. One educator stated that 'social awareness reduces fear and discrimination. Once you understand others and their background you are less likely to fear them, instead you will feel empathy and show respect'. Educators' responses highlighted the importance of being able to empathise with students who experience adversity and live within harsh environments as the foundation for facilitating forgiveness and restorative justice.

\section{Positive learning environment}

Educators or students: Educators commented how SEL skills would contribute to a more harmonious classroom atmosphere and positive learning environment. A sample educator response includes: 'Respect in a classroom between teachers and learners creates a peaceful working environment, which creates successful outcomes'.

\section{Improved educator efficacy}

Educators: The educators felt that SEL skills would contribute to their own personal and professional well-being, because the difficulties within the present learning environment may be ameliorated. In addition, the educators believed that SEL skills would enhance teachers' ability to identify learners who were struggling with barriers to learning, especially the ones with learning and/or emotional difficulties that might have resulted from experiences of adversity.

\section{Self-awareness}

Educators: Self-awareness and social awareness are inexorably intertwined in a multicultural context: 'A teacher needs to be able to be sensitive to what the learner, in their community, deals with in order to lead them into self-awareness'.

Students: The educators believed that students with selfawareness can contribute to a more harmonious and positive learning environment and responsible decision making. Sample responses include: '[self-awareness is] imperative if one wishes to integrate a learner into society and if they have no awareness of self, then they cannot be a contributing member of a team' and 'In order for one to be able to face the outside world and survive, they (learners) need to know who they are and what drives them as individuals'.

\section{Decision making}

Educators: The responses regarding decision making illustrated the need for making decisions regarding right or 
wrong behaviours towards others and the processing of possible outcomes of making the wrong decision. This is illustrated further by one of the educators' remarks: 'Decision-making skills are important for everyday life, especially when it comes to safety concerns regarding our learners'.

\section{Togo}

A total of five SEL themes were derived from Togolese educator responses. It is worth noting that Togolese educators frequently made connections between SEL skills and career development, partly because of the inclusion of career counsellors as participants.

\section{Self-awareness}

Educators: The central theme derived from educator responses was related to learning how to control their own emotions and temperaments as educators in order to maintain good relationships and create a climate of trust with the students.

Students: Educators believed that with self-awareness students become more actively involved in their learning, develop self-efficacy, believe in their plans, achieve academic success and make better career choices. As one educator stated, 'If the students know their strengths and weaknesses, they can easily succeed in their studies, guide themselves through the school curriculum, and make better career decisions'.

\section{Self-management}

Educators: The theme educator referred to the most was emotional self-control. They highlighted the need for teachers to be in control of their emotions and stress, which are crucial for classroom management (for teachers when dealing with difficult students). The second self-management theme identified for teachers to be using was autonomy and self-discipline in relation to the pursuit of their goals (e.g. planning, time management).

Students: The educators also highlighted the need for students to be in control of their emotions and stress, especially when they are going through difficult moments (e.g. failure). According to one educator, these skills will allow students ' $n$ ot $[t o]$ be distracted from the pursued objectives by endogenous factors and allow [students] to reach [their] goals and project [themselves] into the future'.

\section{Social awareness}

Students: Social awareness was identified by the educators as an SEL skill contributing to students' social integration and career development. The skills that contribute to their social integration include sociability, developing good relationships, open-mindedness, developing life skills, empathy, patience, tolerance, indulgence, avoiding racist behaviors and taking the best out of differences. The social awareness skills that contribute to career development include integrating into groups or networks, exchanging knowledge and experiences with others, improving their performance and making friends: '[social awareness] will enable the learner to know how-to live-in society and to avoid marginalist or racist behaviour'.

\section{Relationship and communication skills}

Educators: Educators identified relationship and communication as two related SEL skills that allow them to manage students and classrooms: 'The way we communicate will reflect the degree of trust that may exist between us'. Also, 'each student has his or her own personality, so it is necessary to adapt to [individual students] to get the message across'.

Students: Similar to social awareness, relationship and communication skills allow students to have good integration to groups, thus facilitating learning.

\section{Decision making}

Students: The educators emphasised the importance of students engaging in informed decision making, which helps them to be autonomous and make better career decisions. Moreover, they argued that students need to learn how to make 'judicious' decisions and choices for themselves and also in relation to others. The choices students make should be in accordance with their desires and meet cultural and societal standards. Educators highlighted the importance of complying with social norms, which is important in contexts like sub-Saharan Africa: '[decision-making skill] will help [students]make informed choices in conformity with their desires but also with environmental standards'.

\section{Uganda}

A total of four SEL categories were identified from the Ugandan educators' responses.

\section{Self-awareness}

Educators: The educators mentioned that 'becoming aware of ourselves enables us to concentrate on what we can do better leading to efficiency'.

Students: Recognising strengths, weaknesses and interests and knowing one's identity belong to this category: 'it is important for students to know who they are because it is important for decision making'. Empathy also belongs to this category in the Ugandan context where students become aware of and get concerned about the issues of their fellow students. Educators believed that when students have self-awareness skills, they help and empathise with others, allowing them to have sound judgement about others.

\section{Self-management}

Educators: When students argue, educators reported that teachers should be ready to step in and discuss self-regulation and how to manage emotions. A sample educator response 
includes: 'When two boys were fighting, I talked to them about self-discipline'.

Students: Another educator mentioned that selfmanagement related to improving one's weaknesses can help students attain better life outcomes.

\section{Relationship and communication skills}

Teachers: Educators reported that it is important for teachers to help students build communication skills in order to support them in developing good relationships.

Students: Relationship and communication skills are the most frequently mentioned SEL skills and responses related to this theme included conflict management, creating and maintaining relationships, teamwork and respect for others. A sample educator response includes: 'Through gaining relationship and communication skills young people get social connections in life'. They also believed that having respect for others helps reduce discrimination.

\section{Decision making}

Students: Three themes emerged in relation to decision making, including thinking before acting, mature decision making and situation analysis. A sample educator response includes: 'It is important [for students] to understand the situation before taking action'. The educators considered that understanding circumstances before acting is important, and the decisions that are well thought out can lead to mature decisions and actions amongst students.

\section{Discussion}

This study examined educator perspectives amongst four African countries regarding the nature and value of SEL skills in relation to teaching and working with students, as well as SEL skills students need to successfully transition into adulthood and the world of work. Despite cultural and contextual differences across the countries, seven common SEL themes emerged across the four countries. These themes include self-knowledge, self-control and selfregulation, empathy and compassion, valuing and accepting cultural diversity, interpersonal relationships, decision making and respect. This article adds new information to the field by proposing an SEL framework that aligns to the African socio-cultural contexts whilst acknowledging that there is a need for future studies to add more African countries.

\section{Common social emotional learning themes}

There are seven SEL themes shared amongst Burkina Faso, South Africa, Togo and Uganda. Similar to the thematic analysis process conducted within each country team, the four research teams compared the codes and negotiated what needs to be included in the common themes. The consensus was reached for each of the seven categories by having indepth conversations on each theme, how it is defined in the context of each country or culture, and example responses. Whilst some of the categories overlap with the existing framework of CASEL, such as interpersonal relationships, decision making and self-knowledge (self-awareness), it is our consensus that they are defined narrower or broader in the context of the four African countries and worth examining the differences in order to create quality SEL programmes and activities. Table 1 provides the summary statements of the seven common themes based on the consensus amongst the country teams, followed by detailed explanations on how they differ from the existing SEL frameworks.

Self-knowledge skills consisted of the following competencies:

- being aware of one's strengths and weaknesses

- knowing one's own capacity

- being aware of one's own identity

- seeking to improve their strengths and weaknesses.

The consensus amongst the country teams was that the educator responses reflect the need to be aware of one's identity, emotions, strengths and weaknesses and improve self-knowledge skills to contribute to society. The educators in the four countries used the term self-knowledge more often than self-awareness in responding to the survey. If self-awareness involves understanding ones' thoughts, emotions and values, it is deemed that based on the educator responses, self-knowledge focusses on the awareness of strength and weakness areas that contributes to one's capacity and identity building.

Self-control and self-regulation skills consisted of the following competencies:

- controlling one's own emotions

- managing behaviours and providing a safer classroom environment (educators)

- coping with difficult situations in pursuit of one's goals

- discussing self-discipline with students to help them better manage their emotions (educators).

TABLE 1: Summary statements of seven common social emotional learning themes.

\begin{tabular}{ll}
\hline SEL theme & Summary statement \\
\hline Self-knowledge skills & $\begin{array}{l}\text { Being aware of one's identity, emotions, } \\
\text { strengths and weaknesses and } \\
\text { improving self-knowledge skills to } \\
\text { contribute to society }\end{array}$ \\
\hline Self-control or self-regulation skills & $\begin{array}{l}\text { Being able to control one's emotions and } \\
\text { behaviours in pursuit of their goals }\end{array}$ \\
Empathy and compassion skills & $\begin{array}{l}\text { Being able to tolerate and appreciate } \\
\text { individual differences by understanding } \\
\text { others' contexts and dealing with } \\
\text { possible adversity }\end{array}$ \\
Valuing and accepting cultural & $\begin{array}{l}\text { Understanding social values whilst } \\
\text { respecting cultural diversity that helps us } \\
\text { reduce fear and discrimination, forgive } \\
\text { and repair the harms caused by } \\
\text { conflicting behaviours }\end{array}$ \\
Interpersonal relationship skills & $\begin{array}{l}\text { Being able to create and maintain good } \\
\text { relationships and working together } \\
\text { towards common goals (teamwork) }\end{array}$ \\
Decision-making skills & $\begin{array}{l}\text { Taking into account the opinions of } \\
\text { students and making wise decisions and } \\
\text { judgement about others }\end{array}$ \\
Respect skills & $\begin{array}{l}\text { Used in various learning and work } \\
\text { situations, respect starts from being } \\
\text { aware of one's own identity or } \\
\text { self-respect and involves tolerating } \\
\text { others' points of view }\end{array}$ \\
\hline
\end{tabular}


The consensus amongst the country teams was that the educator responses reflect the need to be able to control one's emotions and behaviours in pursuit of their goals. This allows educators to manage different classroom situations and create a safe learning environment. Although the terms used to describe self-control and self-regulation seem similar to how self-management is defined, they are different because the educators in the study focussed on regulating internal feelings and behaviours and did not necessarily extend to the next levels of self-management skills, such as motivating and taking initiatives. It is understood that the focus on regulation skills is because of the many challenges the students in the four countries are facing in accessing quality education, which asks them to prioritise controlling their current situations.

Empathy and compassion skills consisted of the following competencies:

- expressing concern about and understanding others and their contexts, which allow them to become patient and tolerate differences

- dealing with possible adversity.

The consensus amongst the country teams was that empathy and compassion enable educators to tolerate and appreciate individual differences by understanding others' contexts and dealing with possible adversity. This is consistent with the results of our prior study that focussed on empathy skills across seven countries and suggested a broader definition of empathy (Kounenou et al., in press).

The ability to engage in empathy and compassion is felt by educators to enable them to effectively engage in other SEL themes, such as valuing and accepting cultural diversity, respect and relationship skills. Each of these themes was frequently mentioned by the educators, implying that they may be especially significant for educators from the four African countries.

Valuing and accepting cultural diversity skills consisted of the following competencies:

- teaching social virtues and values

- understanding others' backgrounds, reducing fear and discrimination, forgiving and participating in restorative justice

- valuing diversity whilst complying with social norms

- cultivating group spirit and social cohesion

- making a sound judgement about others.

The consensus amongst the country teams was that by understanding social values whilst respecting cultural diversity, educators are able to help reduce one's fear and discrimination, forgive and repair the harms caused by conflicting behaviours. This helps to rebuild relationships, collaborate and cultivate group spirit, leading to social cohesion. This can ultimately contribute to building empathy and compassion skills. Many SEL skills in this category imply the conflicts that exist in these four countries that challenge students and educators. They suffer from discrimination and racism, and the process of reducing fear and repairing harm is considered one of the important goals that need to be addressed in SEL education. Valuing and accepting cultural diversity is deemed not only a skill one can possess but an important educational strategy that educators can use to address the tension in the classroom.

Interpersonal relationship skills were expressed as a prerequisite skill that contributes to creating a positive learning and work environment. Some unique themes were identified in this category, including equity or fairness in the classroom, relational leadership and being role models for students. The consensus amongst the country teams was that the educator responses reflected the need to be able to create and maintain good relationships and work together towards common goals (teamwork). This helps educators to create a positive learning environment. Although this is a common theme identified across different SEL frameworks, including the CASEL's, the interpersonal relationship skills in the present study are deemed unique because the educators highlight equity in the relationships and leadership development amongst individuals. This implies that the development of teamwork and collaboration can begin by recognising the skills within individuals, and when each student develops leadership in an equitable environment, they are able to create and maintain authentic relationships.

Decision-making skills consisted of the following competencies:

- taking into account students' opinions (educators)

- knowing right and wrong, moral understanding

- making judicious choices for oneself and others

- having students engaged in decision making (educators).

Some unique themes also emerged in this category, including acceptance of the decision-making choices in accordance with one's desire and social norms and maintaining personal safety. The consensus amongst the country teams was that the educators reflected on taking into account the opinions of students and making wise decisions and judgement about others. Whilst decision-making skills typically involve analysing the potential consequences and how they influence oneself, family and the community, many educators who participated in this study raised concern about the lack of involvement of their students in the decision-making process. According to the educator's responses, student involvement is meaningful in three ways: it increases self-confidence, improves leadership and most importantly, helps them learn from the experience how to make 'caring and constructive choices' (CASEL, n.d.). It was also important for the educators that students are more likely to accept the decisions when they are involved in the process.

Respect is a theme that showed the most complexities across the four countries. Each country considered respect within a different boundary or context. The educators in Burkina Faso placed respect under communication and interpersonal relationships and defined it as mutual 
respect amongst students. Burkinabe educators discussed respect in terms of social consciousness defined as students learning how to respect and tolerate others, leading them to forgiveness. The educators in South Africa considered respect as a skill that begins with the ability of being aware of one's own identity (self-respect) within a multicultural context. Whilst learning how self-respect starts at home, South African educators expressed that teachers are often the parents and role models to many students. Similarly, the educators in Togo considered respect a skill that starts from self-awareness. When the educators are aware that they can tolerate differences in opinions, they are able to show respect to others. Similar to Burkina Faso, the educators in Uganda placed respect under communication and interpersonal relationships, and its educators believed that they are able to reduce discrimination through respect. The consensus amongst the country team was that the educators reflected on respect in various learning and work situations. It starts from being aware of one's own identity or self-respect and involves tolerating others' points of view. This helps to reduce discrimination and leads to forgiveness.

It is worth mentioning that many Togolese educators discussed SEL skills in relation to career development, partly because of the participation of career counsellors in the study. The findings show that social awareness, in particular, was important in the career development of Togolese students. By exchanging knowledge with others and networking, the educators believed that the students are able to build skills towards their future careers. Self-awareness, especially being aware of their strengths and weaknesses, also helps students make better career choices. In the decision-making process, the educators strongly believed that it is critical to have students engage in informed decision making so that they can be more autonomous, leading to better career decisions.

\section{Conclusion}

The perspectives of the educators in Burkina Faso, South Africa, Togo and Uganda offer a culturally responsive SEL model that reflects the African contexts as its students and educators face different challenges in school and at home, therefore requiring different SEL skills. Specifically, we focussed on the SEL skills that educators should be using to effectively teach their students, as well as the SEL skills the educators believe students should be using to be effective learners and to successfully transition into the world of work. The seven SEL themes discussed in this article offer a starting point for creating an SEL theory of action (see Figure 1) that reflects the sociocultural contexts of the represented African countries. Our plan for adding more African countries to our analysis enables us to strengthen our framework with more educator responses. The given theory of action lists the strategies to use when implementing SEL education in Africa based on the findings of the present study and the process includes three steps: action, outcome and impact. The seven SEL skills identified in the study are either an action or outcome, with appreciating diversity and decision-making being outcomes that would come after building various foundational

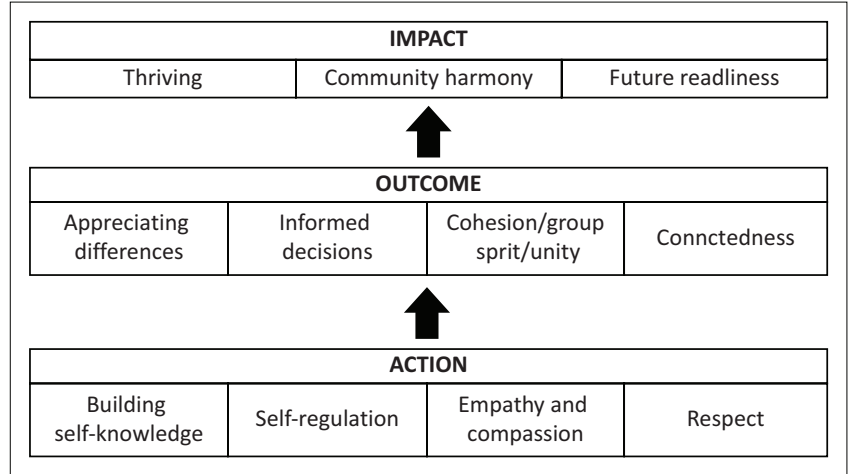

FIGURE 1: Social emotional learning skills theory of action.

SEL skills. As action items, these skills can be developed by focussing on building self-knowledge, self-regulation, empathy and compassion and respect. This in turn will result in the outcomes of increased skills in appreciating differences, informed decisions, cohesion or group spirit or unity and connectedness. Ultimately, this leads to whole-child development and an increased impact on a broader society that can be described as thriving, community harmony and the future readiness (Solberg, Park, \& Marsay, 2020) amongst African youth.

The present study aimed to carefully consider the nature and value of SEL by focussing the conversation on the voices of their respective educators and situating the emerging themes within the context of each African country represented. Given the complexities of culture and politics in Africa, further studies are needed with more countries or cultures in Africa to further refine and define the emerging SEL theory of action and understand how it applies to different country contexts. The present study contributes to the efforts of translating research into practice by examining the perceptions of the educators in the field as a starting point and ultimately plans to use the findings to identify ways to infuse SEL into educational materials, activities and programmes.

\section{Acknowledgements Competing interests}

The authors declare that no competing interests exist.

\section{Authors' contributions}

Each author managed their own data collection, research analyses and write-up. C.M.P. and V.S.H.S facilitated and supported each team, helped to organise the report and provided editorial support.

\section{Funding information}

This research received no specific grant from any funding agency in the public, commercial or not-for-profit sectors.

\section{Data availability}

The data that support the findings of this study are available from the corresponding author, [V.SH.S.], upon reasonable request. 


\section{Disclaimer}

The views and opinions in this article are those of the authors and do not necessarily reflect the official policy or positions of an affiliated organisation or agency of the authors.

\section{References}

Aber, J.L., Tubbs, C., Torrente, C., Halpin, P.F., Johnston, B., Starkey, L., ... Wolf, S (2016). Promoting children's learning and development in conflict-affected countries: Testing change process in the Democratic Republic of the Congo. Development and Psychopathology, 29(1), 53-67. https://doi.org/10.1017/ S0954579416001139

Atitsogbe, K.A., \& Bernaud, J.-L. (in preparation). Vocational values scale: Development and initial validation of the student form (VVS-S).

Bazeley, P., \& Jackson, K. (2013). Qualitative data analysis with NVivo. London: Sage.

Braun, V. \& Clarke, V. (2006). Using thematic analysis in psychology. Qualitative Research in Psychology, 3(2), 77-101. https://doi.org/10.1191/1478088706qp063oa

Burkina Faso. (2007). Loi n $013-2007 /$ AN du 30 juillet 2007 portant loi d'orientation de l'éducation. Ouagadougou, Burkina Faso: Assemblée Nationale.

Cefai, C., Bartolo, P.A., Cavioni, V., \& Downes, P. (2018). Strengthening social and emotional education as a core curricular area across the EU. A review of the
international evidence, NESET II report. Luxembourg: Publications Office of the international evidence, NESET II report. Luxembo
European Union. https://doi.org/10.2766/664439

Cefai, C., Regester, D., \& Akoury-Dirani, L. (2020). Social and emotional learning in the Mediterranean: Cross cultural perspective and approaches. Leiden, Netherlands: Brill/Sense.

Cluver, L., Orkin, M., Gardner, F., \& Boyes, M. (2012). Persisting mental health problems among AIDS-orphaned children in South Africa. Journal of Child Psychology and Psychiatry, 53(4), 363-370. https://doi.org/10.1111/j. 1469-7610.2011.02459.x

Collaborative for Academic, Social, and Emotional Learning (CASEL). (2021) International perspectives resources. Chicago, IL: Author. Retrieved from https:// casel.org/international-resources/

Collaborative for Academic, Social, and Emotional Learning (CASEL). (n.d.). What is social and emotional learning? Retrieved from https://casel.org/what-is-sel/

Dass-Brailsford, P. (2005). Exploring resiliency: Academic achievement among disadvantaged black youth in South Africa. South African Journal of Psychology, 35(3), 574-591. https://doi.org/10.1177/008124630503500311

De Lannoy, A., Graham, L., Patel, L., \& Leibbrandt, M. (2018). What drives youth unemployment and what interventions help? A systematic overview of the evidence and a theory of change. Retrieved from http://www.povertyandinequality. evidence and a theory of change. Retrieved from http://www.povertyandinequality. uct.ac.za/sites/default/files/image_tool/images/95/2018
Youth\%20Unemployment\%20report_181117_interactive.pdf

Department of Higher Education and Training. (2016, June 3). Draft policy: Building and effective and integrated career development services system for South Africa. Retrieved from http://www.gov.za/sites/www.gov.za/files/40041_gon621.pdf

Department of Higher Education and Training. (2019, March 7). National skills development plan 2030. Retrieved from Government Gazette: https://www. chieta.org.za/Portals/0/ndp2030.pdf

Durlak, J., Weissberg, R., Dymnicki, A., Taylor, R., \& Schellinger, K. (2011). The impact of enhancing students' social and emotional learning: A meta-analysis of schoobased universal interventions. Child Development, 82(1), 405-432. https://doi org/10.1111/j.1467-8624.2010.01564.x

Guest, G., \& McLellan-Lemal, E. (2003). Distinguishing the trees from the forest: Applying cluster analysis to thematic qualitative data. Field Methods, 15(2), 186-201. https://doi.org/10.1177/1525822X03015002005

Institut national de la statistique et de la démographie (INSD). (2018). Annuaire statistique 2017. Ouagadougou: Institut national de la statistique.

Jansen, J. (2013). We need to Act. Johannesburg: Bookstorm.

Jansen, J. (2019). Inequality in education: What is to be done? In N. Spaull, \& J. Jansen (Eds.), South African schooling: The enigma of inequality (pp. 355-371). Cham Springer. https://doi.org/10.1007/978-3-030-18811-5

Kaboré, K. A., \& Nabaloum-Bakyono, R. (2014). Socio-psychologie de l'éducation des adultes en Afrique. Hambourg, Germany: I'Institut de I'UNESCO pour l'apprentissage tout au long de la vie.

Kazimna, P., Holu, Y.A., Alfa, A., Tchonda, M., Pari, P., \& Masdonati, J. (2020). What work should be and bring: Representations of decent work in Togo. African Journal of Career Development, 2(1), 1-7. https://doi.org/10.4102/ajcd.v2i1.8

Kim, H., Brown, L., \& Weiss-Yagoda, J. (2017). 3EA education in emergencies: Evidence for action impact report 2.1: IRC healing classrooms remedial tutoring programming improves Nigerien and Nigerian children's learning, New York, NY: Global TIES for Children.
Kounenou, K., Kourmousi, N., Ferrari, L., Suzuki, H., Kanzaki, M., Andrei, A., ... Solberg, V.S.H. (in press). The role of empathy in improving SEL skills among educators and students in era of COVID-19. World Education Research Association, Global students in era of COVID-19. World Education Research Association,
Perspectives on Education Research. Oxfordshire, UK: Routledge Press.

Leoschut, L., \& Kafaar, Z. (2017). The frequency and predictors of poly-victimisation of \& Medicine, 22(sup1), 81-93. https://doi.org/10.1080/13548506.2016.1273533

Lim-Lange, C., \& Lim-Lange, G. (2019). Deep human: Practical superskills for a future of success. Singapore: Epigram Books. ISBN: 9789814845656

Lund, C. (2016). Mental health and human rights in South Africa: The hidden humanitarian crisis. South African Journal of Human Rights, 32(3), 403-405. https://doi.org/10.1080/02587203.2016.1266799

Makota, G., \& Leoschut, L. (2016). The National School Safety Framework: A framework for preventing violence in South African schools. African Safety Promotion, 14(2), 18-23.

Marsay, G. (2020a). A hope-based future orientation intervention to arrest adversity. South African Journal of Education, 40(1), 10 pages. https://doi.org/10.15700/ saje.v40n1a1559

Marsay, G. (2020b, January 20). Social and emotional skills will improve education and grow our economy. Retrieved from thoughtleader Mail and Guardian: https:// thoughtleader.co.za/psyssa/2020/01/20/social-and-emotional-skills-willimprove-education-and-grow-our-economy/

Mfidi, F. (2017). Mental health issues of school-going adolescents in high schools in the Eastern Cape, South Africa. Africa Journal of Nursing and Midwifery, 19(3), 13. https://doi.org/10.25159/2520-5293/2219

Mfidi, F., Thuayagale-Tsheneagae, G., \& Akpor, O. (2018). The TEAM model for mental health promotion among school-going adolescents. Journal of Child \& Adolescent Mental Health, 30(2), 99-110. https://doi.org/10.2989/17280583.2 018.1485570

Mncube, V., \& Maphalala, M. (2014). The dynamics of violence in South African schools. Special Issue of Journal of Sociology and Social Anthropology, 5. Retrieved from http://www.krepublishers.com/The-Dynsmics-of-Voilence.html

Mohlakwana, M. (2013). Care and support for vulnerable children in schools: The case of child-headed families. Journal of Social Sciences, 36(1), 11-18. https://doi.org/ of child-headed families. Journal of Soci
$10.1080 / 09718923.2013 .11893168$

Moyo, Z., \& Perumal, J. (2019). Challenges faced by teachers living with HIV. South African Journal of Education, 39(1), 1490. https://doi.org/10.15700/saje. v39n1a1490

Nsamenang, A.B. (1992). Developmental roots: The West African sociocultural environment. In Cross-cultural research and methodology series: Human development in cultural context: A third world perspective (Vol. 16, pp. 71-96) Thousand Oaks, CA: Sage. https://doi.org/10.4135/9781483326030.n4

OECD. (2016). Higher education and the labour market: What skills strategy for Togo? Paris: OECD Publishing. https://doi.org/10.1787/9789264263901-fr

Romero, R., Hall, J., \& Cluver, L. (2019). Exposure to violence, teacher support, and school delay amongst adolescents in South Africa. British Journal of Educational Psychology, 89(1), 1-21. https://doi.org/10.1111/bjep.12212

Santos, B.D. (2018). The end of the cognitive empire: The coming of age of epistemologies of the south. Durham, NC: Duke University Press.

Skinner, D., Sharp, C., Marais, L., Serekoane, M., \& Lenka, M. (2019). A qualitative study on teachers' perceptions of their learners' mental health problems in a disadvantaged community in South Africa. Curationis, 42(1), 1903. https://doi. org/10.4102/curationis.v42i1.1903

Solberg, V., Park, C., \& Marsay, G. (2020). Designing quality programs that promote hope, purpose and future readiness among high need, high risk youth: Recommendations for shifting perspective and practice. Journal of Career Assessment, 29(2), 183-204. https://doi.org/10.1177/1069072720938646

Spaull, N., \& Jansen, J. (Eds.). (2019). South African schooling: The enigma of inequality a study of the present situation and future possibilities. New York, NY: Springer.

Taylor, R.D., Oberle, E., Durlak, J.A., \& Weissberg, R.P. (2017). Promoting positive youth development through school-based social and emotional learning interventions: A meta-analysis of follow-up effects. Child Development, 88(4), 1156-1171. https://doi.org/10.1111/cdev.12864

Teeger, C. (2015). Ruptures in the Rainbow Nation: How desegregated South African schools deal with interpersonal and structural racism. Sociology of Education, schools deal with interpersonal and structural racism. Sociolog/
88(3), 226-243. https://doi.org/10.1177/0038040715591285

UNESCO-Pôle de Dakar de IIPE. (2017). Rapport d'état du système éducatif national du Burkina Faso, pour une politique nouvelle dans le cadre de la réforme du
continuum d'éducation de base. Ministère en charge de l'éducation et de la formation. Le Pôle de Dakar de I'Institut international de planification de f'éducation, Dakar: UNESCO.

World Education Research Association. (n.d.). WERA international research networks. Retrieved from https://www.weraonline.org/page/IRNsMaster

Yoder, N. (2015). Social and emotional skills for life and career: Policy levers that focus on the whole child. Centre on Great Teachers and Leaders. American Institutes for Research. Retrieved from https://eric.ed.gov/?id=ED558022 